\title{
El hombre en relación con la creación: una mirada teocéntrica"
}

\author{
Fabián Leonardo Rueda Rueda*
}

Recepción: 02 de junio de 2020 • Aprobación: 20 de junio de 2020

\section{Resumen}

El presente artículo busca reflexionar sobre la particularidad del ser humano con respecto a las demás criaturas, en orden a una relación positiva con los entes naturales. Para llegar a este fin, en primer lugar, abordaremos al hombre (imagen y semejanza de Dios) en relación con el mundo, desde una perspectiva bíblica, buscando encontrar el sentido profundo de algunos textos que hablan de la creación. En segundo lugar, miraremos al hombre como agente activo y dinámico en el proceso de plenificación del mundo en lo que respecta al mismo Creador.

Palabras clave: creación, mundo, hombre, dignidad humana, teocentrismo.

* Artículo de investigación producto del semillero de investigación Fuentes para la Historia de la Iglesia y de la Teología de la Facultad de Teología de la Universidad Santo Tomás. Citar como: Rueda Rueda, F. L. (2020). El hombre en relación con la creación: una mirada teocéntrica. Albertus Magnus, XI(2), 85-103. https://doi.org/10.153322/5005413.6395

* Universidad Santo Tomás, Bogotá, Colombia. orcid: https://orcid.org/0000-0001-73708622. Correo electrónico: fabian.rueda@ustantotomas.edu.co 


\title{
Men in relation to creation: a theocentric view
}

\begin{abstract}
This article seeks to reflect on the particularity of the human being regarding other creatures, in order to establish a positive relationship with natural entities. In order to reach this purpose, first of all, we will approach man (image and likeness of God) in relation to the world from a biblical perspective, seeking the deep meaning of some texts that discuss the creation. Secondly, we will look at man as an active and dynamic agent in the process of fulfilling the world in relation to the Creator himself.
\end{abstract}

Keywords: creation, world, man, human dignity, theocentrism.

\section{O homem e sua relação com a criação: uma visão teocêntrica}

\section{Resumo}

Este artigo reflete sobre a particularidade do ser humano em relação às demais criaturas, em busca de um relacionamento positivo com os entes naturais. Para alcançar esse objetivo, primeiro, abordaremos o homem (imagem e semelhança de Deus) e sua relação com o mundo a partir de uma perspectiva bíblica, buscando encontrar o significado profundo de alguns textos que falam da criação. Posteriormente, veremos o homem como um agente ativo e dinâmico no processo de concretização de um mundo em que o próprio Criador é respeitado.

Palavras-chave: criação, mundo, homem, dignidade humana, teocentrismo. 


\section{Introducción}

La reflexión sobre la tergiversación de la relación hombre-mundo y la crisis ambiental tiene una relevancia particular no solo para las ciencias naturales, sino también para las ciencias sociales y para la teología. Dicha relevancia se refleja en pronunciamientos eclesiales y la insistencia de diferentes sectores del saber humano sobre la correcta interacción que debe existir entre el hombre y su entorno natural.

Científicos y teólogos analizan la relación del hombre contemporáneo con la naturaleza y evidencian una actitud frente a la realidad que consiste en ver al mundo solo como un instrumento de producción: la tecnocracia. El papa Francisco afirma que esta perspectiva tecnocrática "supone la mentira de la disponibilidad infinita de los bienes del planeta, que lleva a estrujarlo hasta el límite y más allá del límite" (Francisco, n. $\left.{ }^{\circ} 106\right)$. La actual tergiversación de la relación hombre-mundo no ha tenido resultados favorables para la vida y la plenificación humana; por el contrario, el poder y el tener parecen ser más fuertes, sin importar la suerte de la tierra, cuya degradación sufre todo el género humano.

Afirma Moormann (2005) que “durante este último siglo los seres humanos se esforzaron por conquistar la Tierra definitivamente y por superar todos los males mediante la ciencia. [...] La población en general ha llegado a ser consciente de algunas consecuencias indeseables del progreso tecnológico" (p. 45). De cara a esta realidad, muchos teólogos afirman que el cristiano tiene la importante responsabilidad de colaborar en un proyecto humanitario universal que propenda por cambios sociales y culturales en orden a la integridad medioambiental y de ayudar a dirigir la realidad hacia Dios en virtud de la redención que ha recibido de Cristo.

En la Sagrada Escritura se afirma que la creación es un don que el hombre recibe bajo una responsabilidad particular: el cuidado. Esto debe motivar una acción integral de la Iglesia, tanto en lo espiritual, como en lo material, teniendo en cuenta lo que afirmaba el papa Juan XXIII en su carta encíclica Mater et Magistra del ya lejano 1961:

Por tanto, la santa Iglesia, aunque tiene como misión principal santificar las almas y hacerlas partícipes de los bienes sobrenaturales, se preocupa, sin embargo, de las necesidades que la vida diaria plantea a los hombres, no solo de las que afectan a su decoroso sustento, sino de las relativas a su interés y prosperidad, sin exceptuar bien alguno y a lo largo de las diferentes épocas. (Juan XXIII, n. ${ }^{\circ}$ ) 
Esta acción eclesial integral puede ser iluminada por la interpretación y la comprensión actualizada de los textos del Antiguo (Gn 1 y 2; Sal 8; Sb 1, 14; Sb 9, 9; Si 17, 1-11) y del Nuevo Testamento (Jn 1, 1-5; Ef 1, 3-14; Col 1, 15-20; Hb $1,1-4 ; \mathrm{Hb} \mathrm{11,3;} \mathrm{Ap} \mathrm{21,} \mathrm{1)} \mathrm{que} \mathrm{se} \mathrm{refieren} \mathrm{a} \mathrm{la} \mathrm{condición} \mathrm{de} \mathrm{criatura} \mathrm{de} \mathrm{los} \mathrm{seres}$ humanos y su relación con los demás seres. La relectura de los pasajes bíblicos puede ayudar al hombre a asumir una actitud concreta no solo como criatura, sino también como hijo de Dios, actuando en coherencia con su condición y relacionándose de manera armónica con el Creador, con el prójimo, con la creación y consigo mismo.

Algunos autores han criticado la teología cristiana, afirmando que la interpretación bíblica favorece una tendencia antropocentrista, propiciando actitudes de dominio abusivo del mundo por parte del hombre. El teólogo alemán Jürgen Moltmann (1987), por ejemplo, afirma que "la fe cristiana en la creación, tal como es sostenida en el cristianismo de la Iglesia occidental, europea y americana, es responsable en gran parte de la actual crisis que padece el mundo" (pp. 33-34). Moltmann busca mostrar el sentido genuino de los textos bíblicos referidos a la creación y la condición de criatura del hombre. Al igual que él, muchos teólogos perciben el reto de encontrar el sentido auténtico que subyace en los pasajes bíblicos, en los cuales el centro y el fin último de la creación no es el hombre, sino la misma gloria divina (lectura teocéntrica), la cual procura el bien integral de toda la obra creadora. Sin embargo, la perspectiva teocéntrica de la creación no olvida la importancia particular que tiene el hombre en el mundo como agente dotado de relación, razón y voluntad.

Así las cosas, este trabajo comprende dos partes, a saber: en primer lugar, reflexionaremos sobre el hombre en relación con la creación desde una perspectiva bíblica afirmando el carácter teocéntrico en los textos de la Sagrada Escritura. En segundo lugar, nos acercaremos a algunas comprensiones según las cuales el hombre es agente activo en el proceso de plenificación de la naturaleza en lo que respecta al Creador desde tres puntos de vista: su constitución ontológica, la dignidad del trabajo y la condición de gracia dada en Cristo.

1 Las citas bíblicas del texto provienen de la de la Biblia de Jerusalén de la Escuela Bíblica de Jerusalén (2009). 


\section{El hombre en relación con la creación desde el punto de vista bíblico}

Moltmann (1987) resalta en su lectura del primer relato de la creación el sentido originario al que el autor sagrado se refería en la composición del texto. Efectivamente, el teólogo alemán presenta el desarrollo de una doctrina sabática, concibiendo el último día como la consumación definitiva de la obra creadora. El texto bíblico afirma:

Concluyéndose, pues, el cielo y la tierra con todo su aparato, el séptimo día Dios dio por concluida la labor que había hecho; puso fin el día séptimo a toda la labor que había hecho. Después bendijo Dios el día séptimo y lo santificó; porque en él puso fin Dios a toda la obra creadora que había hecho. (Gn 2, 1-3)

En el sábado se bendice todo lo creado. Muchos creyentes al leer este pasaje, parecen olvidar el sentido que tiene el día séptimo. Moltmann (1987) afirma que "el Dios creador llega a su meta, a sí mismo, a su gloria, precisamente en su reposo sabático" (p. 20). Entonces, la interpretación sabática de la creación puede ser la oportunidad para que el hombre se sienta criatura y obra buena de Dios en un ambiente de relacionalidad y comunión tanto con el Creador como con lo creado porque, como lo afirma Gesché (2002), “Dios crea para dicha suya, para deleite suyo: no hay en esto egoísmo alguno, pues el amor de los otros implica el amor de sí mismo" (p. 134).

Esta profundización con referencia al sábado permite ver que el hombre no es el fin último de la obra creadora, pero tiene un papel importante en la organización progresiva de la creación que se plasma en la Escritura. La perspectiva sabática de la creación, expresada bajo el presupuesto de la salvación divina para con el pueblo de Israel, es abordada por Ruiz de la Peña (1988a) en su texto Teología de la creación: “toda la creación apunta al sábado, sacramento de la alianza y en él desemboca. [...] El orden de la naturaleza está puesto bajo el orden de la historia y esta será historia de salvación" (p. 45). La particularidad humana se afirma en la ubicación que tiene la creación del hombre y las categorías usadas dentro de la estructura del relato:

Dijo Dios: Hagamos al ser humano a nuestra imagen, como semejanza nuestra; que manden en los peces del mar y en las aves del cielo, en las bestias y en todas las alimañas terrestres, y en todos los reptiles que reptan por la tierra. (Gn 1,26) 
El relato de Génesis 1 se desarrolla en un proceso en donde Dios organiza progresivamente los escenarios y los seres vivos que los habitan. En este este proceso, el hombre tiene un papel importante en orden al encargo que el Creador le ha dado: "manden en". Esta expresión puede resultar problemática si se le da una interpretación superficial. Por ello, es importante encontrar el sentido profundo que conlleva el hecho de que Dios haya ordenado al hombre dominar la tierra. Para Boff (2016), “dominar [en hebreo] no tiene el sentido moderno de tener poder sobre el otro y someterlo. Bíblicamente dominar es administrar con cuidado, racionalidad y responsabilidad una herencia recibida" (p. 124). En la traducción latina, Buitrago (2020) afirma: "el verbo latino dominare viene de la palabra dominus que significa señor: aquel que tiene a su cargo la casa (domus)" (p. 9). La palabra dominare y su traducción parecen haber derivado en una connotación negativa del mandato divino hecho al hombre. No obstante, el término no tiene un significado negativo, expresa responsabilidad: la criatura racional tiene la orden de administrar lo que, en términos actuales se podría llamar, "la casa común", es decir, la creación.

En Génesis 1, 26, selem es la palabra hebrea para imagen; etimológicamente, esta expresión traduce sombra, lo cual indica una dependencia, ya que la sombra necesita siempre del original para existir. Efectivamente, en el contexto del relato la existencia del hombre depende de su relación constante con el Creador. Esta condición de relación dependiente hace partícipe al ser humano de una dimensión espiritual. La Comisión Teológica Internacional (Сті) publicó un documento en el año 2004 denominado Comunión y Servicio, en el cual desarrolla la doctrina de la imago Dei:

\footnotetext{
El hombre no es un individuo aislado, sino una persona: un ser esencialmente relacional. Lejos de significar un actualismo puro que negaría el estatus ontológico permanente, el carácter fundamentalmente relacional de la imago Dei constituye la estructura ontológica en el fundamento para el ejercicio de la libertad y de la responsabilidad. (CTI, 2004, n. $\left.{ }^{\circ} 10\right)$
}

El ser humano, creado a imagen y semejanza de Dios, "tiene una dignidad singular dentro del universo. Es un sujeto y no una cosa más; un protagonista y no una parte del decorado" (Lorda, 2009, p. 175). Dicha dignidad ha sido dada por el Creador y hace parte de su ser creatural. El hombre es naturalmente dotado de una capacidad relacional con Dios; su ser tiene la facultad de remitirse 
y amar a Dios de forma consciente y puede conocer su voluntad para ejecutarla efectivamente.

Ruiz de la Peña (1988a) afirma: "el mundo, salido de las manos de Dios no es una magnitud cerrada y conclusa; más bien pasa ahora a manos del hombre para que este lo perfeccione y dirija hacia su fin" (p. 45); sin embargo, el mismo autor continúa diciendo: "entre Dios y su imagen continúa interponiéndose una distancia inconmensurable. Por muy semejante que Dios haya hecho al hombre, este no es, en última instancia, sino criatura suya" (Ruiz de la Peña, 1988a, p. 45). En efecto, la plenitud o finalidad del hombre (aunque su dignidad de imagen y semejanza del Creador le conceda una particularidad concreta frente a las demás criaturas) no está dada únicamente en sí mismo; su realización completa está relacionada íntimamente con la finalidad de toda la creación, la cual, en últimas, tiende al Creador. En otras palabras y siguiendo a Ruiz de la Peña (1988b) en su texto Imagen de Dios. Antropología teológica fundamental, el hombre, dotado de una capacidad singular que lo asemeja a Dios, comparte con los entes naturales su origen y su destino como criatura. El documento Comunión y Servicio continúa diciendo:

Creados a imagen de Dios para participar en la comunión del amor trinitario, los seres humanos ocupan un lugar único en el universo, conforme al plan divino: tienen el privilegio de participar en el gobierno divino de la creación visible. Este privilegio les ha sido concedido por el Creador, quien permite que la criatura hecha a su imagen participe en su obra, en su proyecto de amor y salvación, e incluso en su mismo dominio sobre el universo. Dado que la situación del hombre como dominador es de hecho una participación en el gobierno divino de la creación, hablaremos aquí de él como de una forma de servicio. (сті, 2004, n. $\left.{ }^{\circ} 57\right)$

Estas aclaraciones ayudan a confirmar una interpretación no antropocéntrica de los relatos de la creación, en donde el verbo dominar adquiere matices concretos que se encuentran orientados al servicio en virtud de la dignidad humana, sustentada en la condición de imagen y semejanza del el Creador. De esta manera, se puede llegar a superar el antropocentrismo, sustituyéndolo por una concepción antropológica relacional. Ruiz de la Peña (1988b) afirma:

Precisamente por tratarse de una potestad regia y vicaria, el señorío humano sobre la creación incluye la tutela de lo enseñoreado. Al hombre se le hace 
responsable de la buena marcha de la creación, a la que sirve gobernándola, y a sabiendas de que el verdadero Señor es Dios, no él. (p. 43)

El desarrollo de lo anterior podría concebir al ser humano como el señor que se relaciona de manera efectiva con la creación. La relacionalidad del hombre con lo creado y su acción de señorío-servicio se sustentaría en la actitud divina para con el mundo: Dios actúa no como dominador, sino como conservador y protector, amante de su obra: la cuida y la sustenta. En la Suma contra gentiles, santo Tomás ubica el mandato de gobernar a las criaturas desde la perspectiva de la jerarquía de dignidad de los seres creados y el orden que el mismo Creador ha dado a las criaturas:

Correspondiendo a la divina providencia la conservación del orden en las cosas y correspondiendo al orden que lo ínfimo descienda gradualmente de lo supremo, es menester que la providencia divina llegue hasta lo más pequeño, gradando cierta proporción. Esta proporción consiste en que, así como las criaturas supremas están sujetas inmediatamente a Dios y son gobernadas por Él mismo, de igual manera, las inferiores estén sometidas y gobernadas por sus superiores. (santo Tomás, 1953, III c. 78)

El ser humano, por participar de la virtud providente de Dios de manera más plena, tiene el encargo de gobernar, a ejemplo del Creador y por su delegación a las otras criaturas que no tienen capacidad intelectual. De esta manera, la criatura racional estaría llamada a actuar de manera semejante al Creador, bajo el ejercicio del servicio. Dios se muestra en el Génesis como portador de bendición y autor de la Alianza (García, 2003, pp. 73-74), por tanto, el hombre debe desarrollarse de esta misma forma: bondadosa y relacionalmente con las cosas creadas. Por su parte, el relato del capítulo segundo del libro del Génesis (tradición yahvista) ubica la formación del ser humano al principio de la acción creadora:

Cuando Yahvé Dios hizo la tierra y el cielo, no había aún en la tierra arbusto alguno del campo, y ninguna hierba del campo había germinado todavía, pues Yahvé Dios no había hecho llover sobre la tierra, ni había hombre que labrara el suelo. Pero un manantial brotaba de la tierra y regaba toda la superficie del suelo. Entonces Yahvé Dios modeló al hombre con polvo del suelo, e insufló en sus narices aliento de vida, y resulto el hombre un ser viviente. Luego plantó Yahvé Dios un jardín en Edén, al oriente, donde colocó al hombre. (Gn 2, 4b-8) 
En efecto, el texto se refiere al hombre de una forma particular: Dios lo moldea y le infunde su aliento de vida. Según Ruiz de la Peña (1988a), este relato tiene la intención de presentar no una narración de la creación en sí, sino expresar que la forma como Dios da el ser al hombre viene acompañada de una serie de elementos que hacen especial la acción humana en el mundo (pp. 28-29): todo es creado para el hombre $(\mathrm{Gn} 2,8)$, se le da la potestad de poner nombre a las criaturas $(\mathrm{Gn} 2,19)$ y, sobre todo, se le encomienda el trabajo y el cultivo de la tierra con el fin de cuidar el jardín (Gn 2, 15).

Esta particularidad humana remite a una responsabilidad con respecto a las criaturas: la administración, el embellecimiento y la necesidad de velar en favor de lo que el Creador le ha dado. En otras palabras, el hombre ha sido insuflado con el aliento divino y recibe la facultad de poner nombre a las criaturas (nombrar deja ver una cierta superioridad en el hombre), pero inmediatamente, se le encomienda la responsabilidad de cuidar, cultivar y mantener hermoso el lugar en donde ha sido puesto. En este sentido, afirma Ruiz (1988b): "tal superioridad no significa una supremacía caprichosa o una licencia para abusar arbitrariamente de lo creado. El hombre debe gobernar en nombre de su auténtico Señor, ante el que es responsable de su gestión" (p. 48). Una vez más podemos ver que, si bien el ser humano tiene un lugar particular dentro de las cosas creadas, esta particularidad no se ordena hacia el uso desmedido de lo creado; por el contrario, el Creador concede al hombre la capacidad de relacionarse con las criaturas desde una condición racional y volitiva, para administrarlas a ejemplo del mismo Creador.

La particularidad del hombre, con respecto a las demás criaturas, también se percibe en el Nuevo Testamento, en cuyos textos es preciso señalar dos aspectos importantes: primero, resaltar el lugar que el hombre tiene con respecto a la creación; segundo, iluminar la relación que los seres humanos tienen con el mundo bajo el ejemplo de Cristo como Hijo de Dios y como Salvador. En el prólogo del Evangelio de Juan, encontramos algunos rasgos particulares que tiene el hombre en el plan creador:

En el principio existía la Palabra, la Palabra estaba junto a Dios, y la Palabra era Dios. Ella estaba en el principio junto a Dios. Todo se hizo por ella, y sin ella nada se hizo. Lo que se hizo en ella era la vida y la vida era la luz de los hombres; y la luz brilla en las tinieblas y las tinieblas no la vencieron. La Palabra era la luz verdadera que ilumina a todo hombre cuando viene a este mundo. Y la Palabra se hizo carne y puso su Morada entre nosotros. (Jn 1, 1-5, 9, 14) 
El texto manifiesta que Dios crea por su Palabra (Jn 1, 3), la cual llega, de forma particular, a los hombres (Jn 1, 9). En el contexto neotestamentario, el LogosPalabra es el principio ordenador de las cosas y se identifica con el Hijo de Dios encarnado (Jn 1, 14). Cuando Dios crea el mundo, ya tiene una idea o un proyecto que se plasma a través de la Palabra. El énfasis del prólogo de Juan tiene una clave de lectura desde la visión concreta del capítulo primero del Génesis: el texto joánico busca expresar la plenificación de la creación que sale de Dios, pasando por el mundo y retornando a Él por Cristo. Ruiz de la Peña (1988a) explica esta realidad afirmando una intencionalidad propia del autor sagrado: "resaltar la unidad entre la palabra divina de Gn 1, por la que Dios crea y revela al principio, y la palabra encarnada, con la que la acción y la revelación de Dios llegan a su plenitud" (p. 80).

El Logos divino del que habla el autor joánico es identificado con la Luz, dada a los hombres; Él mismo se encarna en un ser humano concreto. Esto permite afirmar que el hombre no solo es el destinatario consciente de la Luz de Dios, sino que la naturaleza humana es morada de la realidad divina del Hijo de Dios. Esto indica que en el espíritu joánico, "una vez reseñada la obra de la creación, la atención del autor se orienta decididamente hacia la antropología, orillando por completo la cosmología" (Ruiz de la Peña, 1988a, p. 82). El Evangelio de Juan (al igual que muchos textos del Nuevo Testamento) permite ver que el hombre ha sido motivo especial de presencia divina, por lo cual, presenta una relevancia particular en la obra creadora. Esto nos conduce a un segundo elemento: iluminar la relación del hombre con las demás criaturas para promover una conversión ecológica a partir de Cristo a la luz de la Escritura.

En el Nuevo Testamento encontramos elementos que permiten percibir una relación nueva del hombre con Dios. El papa Francisco, en la carta encíclica Laudato $\mathrm{Si}^{\prime}$, refiere esta relación bajo tres perspectivas: primero, el hombre debe seguir el ejemplo del Padre celestial que se relaciona tiernamente con la creación (véase Lc 12, 6); segundo, el ser humano debe tomar una actitud de respeto y contemplación para con la naturaleza, siendo consciente de la belleza y la presencia de Dios en las criaturas. Las constantes referencias que hace Jesús a las dinámicas del campo y de la naturaleza para referenciar el Reino de Dios pueden ser iluminadoras (Mt 13, 31-32); tercero, la actitud del Señor para con las realidades que lo rodean es ejemplo y motivo de admiración. El papa Francisco afirma:

El Señor podía invitar a otros a estar atentos a la belleza que hay en el mundo porque Él mismo estaba en contacto permanente con la naturaleza y le prestaba 
una atención llena de cariño y asombro. Cuando recorría cada rincón de su tierra se detenía a contemplar la hermosura sembrada por su padre, e invitaba a sus discípulos a reconocer en las cosas un mensaje divino. (Francisco, n. $^{\circ}$ 97)

El papa se remite a textos como Mt 6, 26; Mt 8, 27; Mt 13, 31-32 y Mt 11, 19, entre otros, para afirmar que Jesús tenía una positiva relación con las cosas creadas y que, bajo el modelo del mismo Cristo, el creyente debe tomar para sí esta realidad y vivirla en su experiencia de vida.

\section{El hombre, participante activo de la planificación de la creación}

Los textos bíblicos que hablan de la creación permiten expresar una particularidad del hombre, sin que esto signifique un absolutismo en su papel de administrador de la creación. Hemos puesto en relieve el don divino de la imagen y semejanza y la implicación de responsabilidad con respecto al mundo que esto imprime en el ser humano. En este momento centramos nuestra reflexión en las formas como el hombre toma parte activa en el proceso de plenificación de la naturaleza como administrador a imagen del Creador. El papa Francisco, citando a san Basilio Magno afirma que todas las cosas, por su condición de criaturas y en orden a la gloria divina, deben retornar a su Creador: "junto con todas las criaturas, caminamos por esta tierra buscando a Dios, porque, si el mundo tiene un principio y ha sido creado, busca al que lo ha creado, busca al que le ha dado inicio, al que es su Creador" (Francisco, n. ${ }^{\circ} 244$ ).

El hombre, como administrador, ayuda a que la creación vuelva a la fuente de su origen, en cuyo estado se encuentra su plenificación ya que, como lo afirma Martínez (2018), "siendo la Bondad divina el principio de la creación, debe afirmarse igualmente que es el fin último al que se ordena todo lo creado" (pp. 270). Así, el ser humano en el despliegue de sus potencialidades, debe ayudar a las criaturas a retornar a su Creador ya que allí encuentran su estado de plenitud. Santo Tomás, en su Suma de teología, afirma: "todas las criaturas intentan alcanzar su perfección, que consiste en asemejarse a la perfección y bondad divinas" (santo Tomás, 2001, I q. 44, art. 4).

El ser es participación divina. Todos los entes tienen un elemento en común: que existen, tienen ser (santo Tomás, 2001, i q. 45, art. 2). Las criaturas tienen una finalidad intrínseca: desplegar sus facultades naturales para llegar a la plenitud 
de su ser. En otras palabras, Dios dio origen a todo cuanto existe y otorgó una realidad en común a todo: el ser, la existencia. Afirma Roszak (2018) que

la creación consiste en la relación por la que la criatura recibe su ser de Dios de forma permanente, ya que en los seres creados el no-ser es antes que el ser, lo cual significa que las cosas creadas por naturaleza son no-ser. De ahí que necesitan recibir su ser del Creador. (p. 85)

En otras palabras, afirma Lobato (2001) que "Dios es causa del ser, no solo de la producción de las criaturas. Solo Él posee el ser por su propia esencia; todas las demás entidades son entes por participación" (p. 399). Las criaturas, en cuanto desarrollan sus capacidades, están acercándose a la plenitud de su ser, por tanto, se acercan a Dios. El hombre es consciente de la tendencia que tienen las criaturas hacia el Creador. Además, se da cuenta de que Dios participa a los entes su unidad, bondad, verdad y belleza. Afirma Armendáriz (2001) que "solo a través del hombre llegaría Dios a ser plenamente Creador en cuanto que solo por medio de él sería reconocido como tal por su creación" (p. 501). En últimas, el ser humano es quien puede reconocer que Dios ama profundamente la creación al participarle el ser, ya que el acto de crear es realizado bajo la acción de la voluntad, no de la necesidad. Así, la criatura racional se ve impulsada a glorificar a Dios por su bondad y su benevolencia, incluyendo en esta alabanza, a las demás criaturas. Este acto de glorificación solo puede ser llevado a cabo por los seres humanos.

Afirmamos que el hombre desde su carácter de criatura tiene una función especial en orden a la plenificación de la creación. De acuerdo a diversos autores, las acciones humanas en relación con la naturaleza, afirmando el servicio en el gobierno del mundo, pueden situarse en tres aspectos: la constitución ontológica del hombre; el ministerio en orden a la dignidad del trabajo humano y la tarea de glorificación divina en la cual, el hombre, transformado por la gracia, hace partícipe a toda la creación de la alabanza al Creador. Acerquémonos un poco a cada uno de estos elementos.

Cuando nos referimos a la acción humana en orden a su constitución ontológica, decimos que Dios mismo concede facultades particulares a cada uno de los seres que crea y que mantiene en el ser; Él mismo permite que las despliegue para que, con ayuda de dichas capacidades, lleguen a su fin último. Buitrago (2020) asevera que "Dios le concede a cada criatura la existencia bajo una modalidad particular, [...] no coarta las cualidades que Él mismo le dio a cada criatura: al contrario, le 
da la posibilidad de existir con esas características particulares" (p. 7). Por esto, el hombre debe desplegar sus facultades propias: razón, voluntad, inteligencia, entre otras, porque es gracias a estas que él puede llegar a su fin en la felicidad y la salvación.

De esta forma, también podemos constatar que las criaturas buscan la supervivencia y el perfeccionamiento de su especie en constante relación con las criaturas. En últimas, volvemos a decir que se trata de un retorno al Creador (santo Tomás, 2001, i q. 44, art. 4). El ser humano también se encuentra inmerso en la dinámica creatural de vuelta a Dios, tendiendo a la perfección de su ser, pero en él se presenta una peculiaridad concreta dada por quien lo creó: ser consciente de su sendero hacia la plenitud, relacionándose libremente con la realidad trascendente. En otras palabras, "a diferencia de las otras creaturas que vemos en el mundo, en los seres humanos el acercamiento (o alejamiento) a la realidad divina se hace de un modo libre y consciente" (Buitrago, 2020, p. 13).

La libertad y conciencia permiten al hombre reconocer la dinámica teleológica de la naturaleza, tomar conciencia de su condición de creatura y su rol de administración en orden a la plenitud de todas las cosas para la gloria divina. Buitrago (2020) refuerza esta idea afirmando: "el ser humano por su razón y voluntad está llamado a comprender, respetar y seguir ese orden que el Creador imprime en las creaturas" (p. 8). De esta forma, de acuerdo con Martínez (2018), la criatura se va plenificando en la medida que va buscando la plenitud del ser, es decir, la búsqueda de la bondad divina (p. 270). Este movimiento lo realiza de dos formas: según su inclinación natural hacia la perfección propia e imitando a Dios en la comunicación del propio bien a otros, en la medida de lo posible (santo Tomás, 2001, I, q. 19, a.2).

Cuando hablamos de dignidad del trabajo en el gobierno de la creación, la reflexión debe iniciar con dos apuntes: en primer lugar, afirmando con Chenu (1966) que la fe cristiana no concibe la creación como una realidad que ha sido hecha de forma definitiva, sino que el mismo Creador ha querido que el universo sea una realidad perfectible (p. 538). En este orden de ideas, el hombre tiene la capacidad de contribuir, de manera activa, en la perfección del universo con sus obras, con su trabajo. Esta acción humana, ordenada a la perspectiva del trabajo, se sustenta en sus capacidades particulares de libertad, razón y voluntad.

En segundo lugar, la creación no es una realidad que ocurrió en un momento determinado y concluyó definitivamente. Por el contrario, es una acción que constantemente se va renovando. En esta renovación constante de la obra creadora, el hombre tiene la tarea de actuar. Chenu (1966) lo afirma de la siguiente 
forma: "endentemos por creación no solo el acto inicial de Dios in principio, sino la acción permanente de una creación continua, en que el hombre es su mandatario, libre y responsable" (p. 538). A partir de este concepto perfectible de creación, los hombres tienen la capacidad de orientar las cosas al Creador a partir de su trabajo, desplegando las facultades dadas y obedeciendo al mandato divino en el concurso de la acción plenificadora de los entes materiales.

En efecto, el trabajo humano es importante porque por medio de este el hombre imita al Creador en el ejercicio de la creación continua y ayuda en el proceso de perfección del universo. Chenu (1966) afirma: “Dios llamó al hombre para que fuera su cooperador en la organización progresiva de un universo, en el cual, él mismo debe ser, de esta manera, la imagen de Dios"' (p. 538). La criatura racional se asemeja a su Creador en cuanto al servicio y la conservación de la obra creada, ejerciendo sus facultades en pro de la participación de la bondad divina a las criaturas: el hombre "es el encargado de reunir en sí [los seres de la naturaleza] cuyos últimos grados son evidentemente incapaces de inteligencia y de amor, y, por consiguiente, incapaces de volver por sí mismos a su Creador" (Chenu, 1966, p. 540).

El trabajo humano se constituye en el cumplimiento del mandato dado por el Creador para el cuidado y la administración de la obra creada. Tomás de Aquino evidencia esta realidad al afirmar que el hombre es puesto en el jardín con el encargo concreto de trabajarlo y custodiarlo: de este modo, "se puede entender que el hombre trabajara y custodiara el Paraíso. Pero esto no sería penoso como lo es después de aquel pecado, sino que sería agradable para ejercitar una capacidad natural. [...] Todo esto redundaba en el bien del hombre"' (santo Tomás, 2001, I, q. 102, a.3).

Podemos evidenciar que el trabajo humano tiene elementos que resaltan su valor, en orden a la plenificación de la creación: en primer lugar, es una realidad que la misma naturaleza humana está llamada a desplegar para su conservación. En segundo lugar, es una acción que asemeja y evidencia la semejanza divina en el hombre, por tanto, el trabajo humano se orienta a la conservación de los seres. En tercer lugar, si el paraíso, como lo expresa santo Tomás, se ordena al bien del hombre, este debe actuar conforme a su naturaleza para conservarlo. La degradación del mundo, provocada por el desorden y el desequilibrio natural ocasionado por el ser humano, se constituye, simultáneamente, en deterioro de su misma realidad.

Al reflexionar sobre el hombre agraciado, agente de glorificación divina por y con las criaturas, nos podemos dar cuenta que el hombre reconoce que ha sido 
llamado para un destino celeste, eterno y de divinización. Desde el punto de vista de la reflexión teológica, la criatura humana es convocada a la eternidad. No obstante, su realidad ontológica le impide alcanzar por sí misma este estado de plenificación. Por tanto, el hombre recibe de Dios los elementos necesarios para llegar a su fin último: la gracia. En efecto, Ruiz de la Peña (1991) afirma que

El enigma de lo humano radica, a fin de cuenta, en la imposibilidad humana de realizar su más auténtica y originaria posibilidad. Creando al hombre, Dios ha querido crear un ser finito, pero llamado a la infinitud. [...] Lo que el hombre es por gracia, se trascenderá hacia lo que debe ser por gracia. (p. 21)

El ser racional agraciado tiene la capacidad de trascender su propia naturaleza para encontrar la realidad divina a la cual está llamado. No obstante, esta vocación no es dada solo para el hombre, sino que puede ser considerada un punto de apoyo en el cual Dios quiere que toda la creación se beneficie. El teólogo norteamericano William Jenkins (2008) afirma que "en el acto de su propia santificación, los humanos desempeñan un papel ecológico que no está disponible para otras criaturas: reúnen litúrgicamente el deseo específico de cada criatura por la bondad divina y lo elevan hacia Dios en unión”2 (p. 141).

También podemos señalar que Cristo manifiesta la plenitud de la bondad divina a través del mandamiento del amor (Mt 5, 43-45, 48). En la caridad, entendida como virtud teologal (1 Cor 13,1-13), Dios hace que el hombre transformado por la gracia incluya a las criaturas en su camino de plenitud. Siguiendo a Jenkins (2008): "el universo en su conjunto, al buscar sus propios bienes, desea ser incluido en el amor humano a Dios porque, por la forma de la caridad de los humanos, ellos también alcanzan su propio fin en la bondad divina"3 (p. 142).

A partir de la virtud de la caridad, se manifiesta, en toda la creación, la gracia divina, dada de forma particular al hombre y a través del cual Dios atrae a todas las cosas para llevarlas a su fin último. A través de la realidad humana el Creador efectúa la salvación de todo lo que ha creado, ya que "Dios no solo

2 La traducción de las citas del texto son propias. "In the act of their own sanctification humans perform an ecological role unavailable to other creatures: they liturgically gather together every creature's specific desire for divine goodness and lift it toward God in union" (Jenkins, 2008, p. 141).

3 "The universe as a whole, by seeking their own goods, desire to be included in the human love for God because by the manner of human charity, they too attain their own final end in divine goodness" (Jenkins, 2008, p. 142). 
perfecciona a los humanos a través de su relación especial con la creación; Dios perfecciona la creación a través de su relación especial con la humanidad"4 (Jenkins, 2008, p. 141).

\section{Conclusiones}

Esta relectura del lugar particular que tiene el hombre en la creación, nos permite proponer un cambio de perspectiva en la reflexión antropológica, tomando distancia del antropocentrismo tecnocrático para ubicar en el centro de la realidad creada no al ser humano, sino a Dios mismo en orden a la plenitud de todas las cosas. De esta manera, proponemos un descentramiento humano, para ubicar en el centro al Creador, como conservador del ser de las cosas (santo Tomás, 2001, I q. 104, art. 1), y en quien todas las criaturas encuentran su plenitud. Afirma el teólogo jesuita Roman Guridi (2019):

Un desafío importante para el lenguaje teológico es saber decir, por una parte, la pertenencia de la humanidad a la comunidad de la creación con la que comparte un mismo origen, una misma historia, y un mismo futuro $y$, al mismo tiempo, el lugar y rol particular de los seres humanos que los distingue y separa de las demás criaturas no solo desde el punto de vista práctico sino también ontológico. (p. 19)

En efecto, el ser humano no es solo una parte más de la naturaleza, también es un ser con realidades particulares y facultades únicas que lo ubican en un lugar concreto dentro del orden de las cosas. Se resalta la necesidad de concebir al hombre desde su condición creatural, la cual no contradice su particularidad y dignidad dentro de la misma creación. Müller (2009) resalta que

[...] esta condición de ser creado, de criatura, significa que el hombre, de acuerdo con su realidad total, en su existencia y en la consumación de su naturaleza corpóreo-espiritual, está constituido exclusiva y globalmente por una relación trascendental a Dios con su origen y su fin. (p. 109)

4 "Not only does God perfect humans through their special relation to creation; God perfects creation through its special relation to humanity" (Jenkins, 2008, p. 142). 
Esto no significa una pretensión de superioridad, por el contrario, la idea de ser humano que se formaría desde un teocentrismo ayudaría a constituir a la humanidad en agente de responsabilidad y compromiso activo con el equilibrio y la salud integral de la creación, no solo en pro de su misma conservación biológica, sino, también, bajo la convicción teologal de colaborar efectivamente en la glorificación del orden natural, en donde Dios será todo en todos (1 Cor 15, 24).

Así las cosas, se resaltan elementos que consideramos importantes para que se produzca un cambio de actitud y una acción concreta del cristiano. La idea de relacionalidad que se gesta en ambientes y reflexiones teológicas no se limita a una realidad bidireccional entre Dios y el hombre. A ejemplo del Creador y tendiendo hacia Él, el hombre debe considerar, como elemento de vital importancia para su existencia y su plenificación, la relación efectiva con las demás criaturas. En este sentido, la perspectiva teocéntrica no excluye la dignidad propia del hombre, pero tampoco desprecia la importancia concreta que tiene el mundo, buscando, de esta forma, un equilibrio que permita caminar hacia horizontes de salvación y de plenificación. Afirma Armendáriz (2001):

Si el mundo y el hombre no existen ni se pueden pensar si no es interrelacionados, la teología entiende que ambos mantienen un vínculo aún más estrecho con su Creador; que solo por Él y en Él tienen últimamente ser y sentido y que, por tanto, han de ser vistos a su luz. [...] No se puede hablar adecuadamente del hombre y del mundo silenciando a Dios. Y también, aunque en un sentido diferente, solo se puede hablar bien de Dios tratando del mundo y del hombre, es decir, implicándole en ellos como su Creador. (p. 14)

El teocentrismo permite encontrar en las relaciones hombre-mundo un sentido concreto de salvación y de plenificación. El carácter relacional que se presenta en el ser humano y su dignidad (como imagen y semejanza del Creador) le impulsan a buscar el bien, la bondad y la belleza de sí mismo y de las demás criaturas. El ser humano despliega las potencialidades dadas por el Creador, entendiendo que cada naturaleza tiene una finalidad otorgada. Así mismo, la Escritura expresa un mandato que el hombre está llamado a cumplir: cuidar, conservar, contemplar y reconocer la grandeza divina en la creación. Podemos terminar reflexionando con Benedicto XVI (2016):

Cuando el hombre vive en la plenitud, en la riqueza, en la belleza y en la grandeza es siempre consciente de que su existencia es una existencia donada; sabe 
que justamente es lúcido y grande cuando se ve, no como una creación propia, sino como un regalo que es anterior a mí, que me concibe con su bondad antes de que yo haga nada y que por tanto me pide que dé sentido a esa riqueza para que así tenga sentido. (p. 89)

\section{Referencias}

Armendáriz, L. (2001). Hombre y mundo a la luz del Creador. Ediciones Cristiandad.

Benedicto XVI. (2016). Introducción al cristianismo. Ediciones Sígueme.

Boff, L. (2016). La Tierra en nuestras manos. Editorial Sal Terrae.

Buitrago, F. (2020). La clave está en la relación. Manuscrito presentado para su publicación.

Chenu, M. (1966). El Evangelio en el tiempo. Editorial Estela.

Comisión TeológicaInternacional(сті).(2004).Comuniónyservicio.Lapersonahumanacreada a imagen de Dios. стा. http://www.vatican.va/roman_curia/congregations/cfaith/ cti_documents/rc_con_cfaith_doc_20040723_communion-stewardship_sp.html

Escuela bíblica de Jerusalén (2009). Biblia de Jerusalén (4. ㄹ ed.). Desclee de Brower.

Francisco (2015). Carta encíclica Laudato Si' del Santo Padre Francisco sobre el cuidado de la casa común. Libreria Editrice Vaticana. http://w2.vatican.va/content/francesco/es/ encyclicals/documents/papa-francesco_20150524_enciclica-laudato-si.html

García, F. (2003). El Pentateuco. Editores Verbo Divino.

Gesché, A. (2002). El hombre. Ediciones Sígueme.

Guridi, R. (2019). Pistas para renovar la antropología teológica desde una ecología integral. Lectio inauguralis magister en ciencias religiosas y filosóficas. Palabra y Razón. Revista de Teología, Filosofía y Ciencias de la Religión, (16), 9-22. https://doi. org/10.29035/pyr.16.9

Jenkins, W. (2008). Ecologies of Grace. Oxford University Press.

Juan XXIII. (1961). Carta encíclica Mater et Magistra de su Santidad Juan XXIII sobre el reciente desarrollo de la cuestión social a la luz de la doctrina cristiana (13. ${ }^{\mathrm{a}}$ ed.). Ediciones Paulinas.

Lobato, A. (2001). El Pensamiento de santo Tomás de Aquino para el hombre de hoy (Tomo II). Editorial Cultural y Espiritual Popular (Edicep).

Lorda, J. (2009). Antropología teológica. Ediciones Universidad de Navarra (Eunsa). 
Martínez, E. (2018). El hombre, responsable de la creación. La participación del hombre en el gobierno divino del mundo según san Tomás de Aquino. En S. Bonino y G. Mazzotta (Eds.), Dio creatore e la creazione come casa comune. Prospettive Tomiste (pp. 267-296). Urbaniana University Press.

Moltmann, J. (1987). Dios en la creación. Ediciones Sígueme.

Moormann, K. (2005). Teología de la creación de un mundo en evolución. Editores Verbo Divino.

Müller, G. (2009). Dogmática. Teoría y práctica de la teología. Herder Editorial.

Roszak, P. (2018). Creación en cuanto relación en santo Tomás de Aquino. En S. Bonino y G. Mazzotta (Eds.), Dio creatore e la creazione come casa comune. Prospettive Tomiste (pp. 77-102). Urbaniana University Press.

Ruiz de la Peña, J. (1991). El don de Dios. Antropología teológica especial. Editorial Sal Terrae.

Ruiz de la Peña, J. (1988a). Teología de la creación (6. a ed.). Editorial Sal Terrae.

Ruiz de la Peña, J. (1988b). Imagen de Dios. Antropología teológica fundamental. Editorial Sal Terrae.

Ruiz de la Peña, J. (1991). El don de Dios. Antropología teológica especial. Editorial Sal Terrae.

Tomás de Aquino, S. (2001). Suma de teología (4. ${ }^{a}$ ed.). Biblioteca de Autores Cristianos.

Tomás de Aquino, S. (1953). Suma contra gentiles (Tomo II). Biblioteca de Autores Cristianos.

Tomás de Aquino, S. (2001). Suma de teología (4. ㄹ ed.). Biblioteca de Autores Cristianos. 